\title{
Methods and Tools to Reorganise the Governance in the Italian Healthcare Companies
}

\author{
Daniele Gervasio ${ }^{1}$, Andrea Amaduzzi ${ }^{2}$ \& Damiano Montani ${ }^{1}$ \\ ${ }^{1}$ Università degli Studi di Bergamo, Italy \\ ${ }^{2}$ Università deli Studi di MIilano-Biccocca, Italy \\ Correspondence: Daniele Gervasio, Daniele Gervasio, Università degli Studi di Bergamo, Italy. E-mail: \\ daniele.gervasio@unibg.it
}

Received: November 11, 2016

Accepted: January 20, 2017

Online Published: January 26, 2017

doi:10.5539/ijbm.v12n2p56

URL: http://dx.doi.org/10.5539/ijbm.v12n2p56

\begin{abstract}
This paper is a first analysis of the tools required to convert the fiscal data gathered from the management control systems into official guidelines for a long-lasting healthcare governance.

This paper proposes some reflections about the peculiarity of the cost monitoring and management systems whose configuration and effectiveness must take into consideration the nature of the information requirement of the management processes addressee.

The innovative aspect is to convey all the potential information contained in the cost monitoring systems. In fact, the information represents the subjective aspect, in other words what the reader 'understands' and perceives.

These tools may not be analysed from a mere technical point of view, instead they must be considered as essential means to manage complex corporate systems.

Using Amaduzzi's theories and following an exploratory approach, this paper proposes some considerations about the tools required to convert the acts of management into (economic) values. Then, these values will convert into acts of management thanks to their capability to meet the information requirement of the governance stakeholders.

The analysis carried out highlights the information requirement to satisfy through a series of monitoring and management tools, in order to find organisational and management solutions that are able to combine the need to rationalise the healthcare expenditure and to improve the quality and pertinence of health care services.
\end{abstract}

Keywords: governance, NHS, performance audit, process management,

\section{An Overview on the Managementisation Process in the Healthcare Company}

As is commonly known, the health sector is a highly regulated sector where the main features (financing, programming, purchasing, production) are shared among different stakeholders - that have not necessarily a hierarchical order. In particular, production is largely outsourced to producers not belonging to the public institutions as holders of the social protection role.

In 2008, for instance, institutional social and health care financed by the NHS was offered by 1,419 public facilities $(26.7 \%$ of the total amount) and 3,901 accredited private facilities ( $73.3 \%$ of the total amount) (Ministry of Public Health, 2011). In the same year, semi-institutional care had 979 public facilities (41\% of the total amount) and 1,367 accredited private facilities (58,3\% of the total amount).

Though a slight positive trend is observed in the public sector, the longitudinal analysis between 2005 and 2008 shows a high increase of the number of accredited private facilities in the abovementioned sector.

The fragmentation of functions imposes a wider overlook on the sector in general, observing funds, clients and producers must be taken into consideration - that does not necessarily coincide (G. Fosti, O. Larenza, F. Longo, \& A. Rotolo, 2013).

Doubtlessly, a crucial role in the public healthcare system in Italy is played by all the healthcare companies as well as by their relationships with policymakers in the healthcare sector, such as Ministries, the National Agency for the regional healthcare services, regional healthcare agencies and regions and, as a consequence, by the 
planning of healthcare expenditure and the services offered on the territory. These service providers represent the efficiency of the public health system and are directly involved in the effectiveness of patients' treatment (in a sort of direct contact between the healthcare company and the final user/patient).

In Italy, the renewal process of NHS has been taking place for over two decades - Legislative Decrees $\mathrm{n}$. $502 / 1992$, n. 517/1993 and n. 229/1999. Nevertheless, the study of organisation, management and information requirement of the health system and their stakeholders (regions and businesses) is more and more a current matter and highlights the need to develop solutions that are able to adapt to the future sustainability issues of the public health protection.

In particular, organisational changes rely on the modification of pooling criteria of the activities, on the introduction of intermediate liability levels and on a higher articulation of the organisational structure. An example is represented by the departmentalisation process of healthcare companies that is considered as the crucial aspect of the organisational change as a single business. In fact, in the traditional model based on operational departments, on the centrality of the figure of the physician and on a vertical hierarchy the organisational structure of the hospital seemed to be very fragmented in terms of operational specialised units and full of activities and process duplicated that are not coordinated and integrated with the various medical specialisations.

The necessity to overtake these inefficiencies is at the basis of the legislator's choice to reorganise the operational units into departments. Particularly, the department is an agglomeration of operational units - similar or complementary in the activity carried out - characterised by the same objectives, interdependence, operational autonomy and professional liability. Therefore, the organisational structure of the department allows the unification in operational units having similar specialisations in order to foster an integrated vision of clinical and care processes as well as the sharing of professional resources and expertise. The purpose of the Department is to cancel the overlapping and duplication of the activities - as it happened in the previous model - in order to go beyond the sectorisation of the care process. The Department gave life to many advantages such as the increase of the flexibility and efficiency in the use of the resources to reduce costs, the integration improvement among the various players and the improvement of the service offered to patients in general. In fact, replacing the traditional approach in which the specialisation was more important than coordination, with the creation of the Department made possible for the divisional structure to be the new model used in the national health system. As reported by the Legis-lative Decree 229/1999, the departmental organisation is the conventional model of operational management of all healthcare companies (art. 17a).

Actually, the departmental model is of interest for all hospitals (and their department) having local department or prevention department, such as the Department of Mental Health or the Department of Prevention. The Departments carry out both welfare services giving help to organisational units of the Department and coordinating the resources required to achieve the Department's goals.

The head of the Department is the person in charge of the functions liability. As provided by the Legislative Decree n. 229, the head of the Department is the owner of his/her complex hospital structure. The same legislative decree gives him/her all the clinical- and organisational-related professional liabilities as well as those concerning prevention. Also, he/she has administrative liabilities in terms of accurate programming and resource administration assigned to realise the objectives set. In addition to the head of the Department, there is another authority: the Department Committee, i.e. a collegial authority appointed by regions as for structure and roles. The business management is in charge of gathering the operational units. As explained in literature, below are the different methods and criteria of departmental aggregation:

- methods of aggregation by nosological entity: the operational units are grouped in the departments on the basis of the pathologies and diagnostic category (for instance cardiovascular, oncological, infectious disease, mental health, etc.);

- methods of aggregation by care intensity: the reorganisation of operational units in departments takes into account the different level of hospitalisation needed (for instance Intensive care unit, re-habilitative therapy, day surgery);

- methods of gathering by medical specialty: the gathering into operational units is made on the basis of the relative specialisation area (for instance medicine, surgery, orthopaedics, magnetic resonance imaging).

At present, hospitals are characterised by autonomy, decisional independence and durability. In particular, autonomy reveals decisional, strategical and operational independence as well as the economic self-sufficiency of the business. The acknowledgement of institutional and operational autonomy (R. Tarricone, 2012) to the 
bodies in charge of production and care service provision is the main principle for the managementisation of the public healthcare system.

Durability is tightly related to the pursuing of the principle of cost-effectiveness that identifies each economic institute set to continue to exist in the future. Also, the healthcare organizations have to focus on the research and maintenance of a long-lasting economic functionality. Thus, the public healthcare company is an autonomous coordinated system made of economic resources that commissions and conducts the economic activity (input and output) of medical care aiming at satisfying the healthcare needs in a durable and balanced environment.

Before the reforming process, each healthcare company had some restrictions in making strategic choices. In fact, in the previous model the structure was closed because of a low level of independence of the companies in defining their organisational set up (M. Bergamaschi, \& E. Cantu', 2000). After the managementisation process, the increase of independence and liability of the economic activity still pushes the healthcare companies to redefine their internal organization (A. Cicchetti, 2004).

As for the international scene, medical systems all over the world are different due to the role of the public sector in the public health protection system, which is tightly connected to the welfare status of a country.

According to a study carried out by the Committee of the Regions, which outlines a categorisation of the healthcare systems in the European Union, the types of hospital governance are tightly connected to the level of decentralisation of the systems of healthcare management. The process of aggregation shows five systems of healthcare management in Europe depending on the role of local and regional subjects. The first category includes the decentralised systems, i.e. de facto "regional healthcare management system", namely all the systems where the responsibility for regulation, operation and co-financing are delegated to the regional administration (Italy and Spain) or to the Government (Austria). However, in some healthcare management systems local and regional bodies have executive, programming and co-financing functions. In this model, too, local and regional bodies hold and manage the health care network. Another category refers to healthcare management systems where local and regional bodies manage the operational (executive) functions, as they also own the health care network - including the situation of the Netherlands and the United Kingdom, although it is slightly different. In the Netherlands, the hospital governance is centralised though local and regional bodies have a role in programming and implementation, as well as providing a limited financial contribution through the sub-national budget. In the United Kingdom, each of the four founding Nations (Great Britain, Scotland, Wales and Northern Ireland) has its own "national health system" managed by the single country.

The last two categories are characterised by centralised systems or, in some case, centralised but also locally organised. In the last cluster, most of the power is in charge of the central government, though the implementation is made locally through bodies and agencies representing the central administration. Moreover, its local and regional bodies may manage the health care network, too, made exception for Portugal.

\section{A Systemic Approach for a Long-Lasting Economic Balance}

As a result of regionalisation process of healthcare and change in the previous structures, the heterogeneity of organisation had an impact on the way in which the companies operate. As showed by some more recent empirical research, companies must cope with the coordination and integration problems of the different functions and specialisations, even if the redefinition of internal organisation was introduced with the departmental model. Also, the level of productivity and efficiency, of accuracy and performance quality must be improved. All this encourages aspiring to state-of-the-art organisational solutions that are able to allow an efficient management of clinical activities, processes and treatments to maximise the value for the patient.

The need to improve the medium and long-term planning as for resource allocation (such as the need to stimulate structural and technological investments that have been reduced to contain the expenditure in the last few years, to avoid the halt in the recruitment to reduce input expenditure as well and, finally, to avoid under treatment situations due to a cost cutting policy) validates and stimulates the analysis of the healthcare system of the country having an economic and business approach. This implies the application of the corporate discipline methods to the above-mentioned system and is part of the international studies and theories of the New public management (Npm) and its evolution into Public Governance that affects the public sector companies in terms of accounting, governance and management changes.

From this viewpoint, the traditional studies in business economics take inspiration from the business as a system and mixture of sub-systems. This is why the elements of the healthcare companies proper functioning must be found in their organisation (sub-system of the organisa-tion), in their management procedures (sub-system of the management) and in their accounting and management systems. All this considering that the business is a unitary 
and systemic entity. In other words, the factors that influence the functionality of healthcare companies must be observed with respect to the three phases of the administrative action: organisation, management and audit as explained by the traditional corporate theory. This is why there is an increasing need to study these phases as a system: the analysis of the business systemic unit allows to check its integrated operation and, as a consequence, gives the actual content to the managementisation of healthcare organisations.

Managementisation should not be meant as the denial of the professional autonomy or patient-oriented system or minimisation of costs or maximisation of 'profits'. Instead, it is an approach that requires pursuing their objectives and satisfying the expectations of their stakeholders using all the resources at their best. Thus, managementisation for healthcare companies means that they always have to seek alternative ways to gather and use the resources not having to decrease the satisfied needs, but better to improve them. Moreover, it is necessary to verify that the needs satisfied are the most relevant.

The need to avoid any situation of inefficiency and inefficacy that affects the healthcare system has as main goal to optimise the use of the available resources for the future sustainability of the service. Thus, modern healthcare companies have to combine management efficiency with the increase of support quality standards.

This must be done without ignoring that the final objective of the renewal process of the health system is the capability of National Health System to meet the various needs of the patients on which companies must focus on so as to continuously improve and respect the cost-effectiveness. Therefore, the investigation on the long-lasting economic operation of healthcare companies is mainly oriented to treatments to safeguard the inalienable right of citizens to health and welfare.

Moreover, at present we outline a different attention to care and clinical needs of patients in order to assess the efficacy and accuracy of treatment processes. With regard to this, a "National Outcome Programme" (i.e. Pne Programma nazionale esiti) 2013 by the Ministry of Public Health and the National Agency for Regional Health Services (i.e. Agenas - Agenzia nazionale per i servizi sanitari regionali) was prepared to improve the efficiency and fairness of the NHS through the detection of the factors of health processes that determine the results of the actions to be able to carry out a comparative assessment successively.

The work of economy and corporate researchers and professionals of this sector analyses the variables that determine the long-lasting economic functionality of the healthcare companies (the long-lasting economic balance). This leads to conceive the healthcare company as a combination of elements gathered in a system whose integration is oriented to pursue a shared objective: the safeguard of individual and collective health, which is more and more influenced by a limited availability of the resources necessary to satisfy it.

Starting from this theory, this work wanted to confirm the systemic approach introduced after Gino Zappa in order to provide an overview of the public healthcare company.

The process of modernisation and 'business' change of the public health system has been the subject of the academic debate for years both at a national and international level. The purpose of these studies has been to find organisational and management solutions that are able to combine the need to rationalise the healthcare expenditure and improve the quality and pertinence of health care services.

As a result of the abovementioned framework, the objective of this research is to provide a first analysis of state-of-the-art business experiences to identify new trends both in terms of organisational models and expertise to suggest reflections on the tools required to convert the act related to management into economic values by means of the economic performance audit of the business. And these, in their turn, convert into act of management for their capability to meet their information requirement of the governance stakeholders.

\section{The new Trends in the Governance Structures}

As for hospitals, their role in the healthcare systems and, in particular, the conditions in which the evolution may be "rationally" led (birth, changes, closing, rebirth in different forms), the debate is long-standing. In other words, some crucial elements remained unaltered over the decades and, at the same time, have experienced deep changes as the concept of hospital itself and the relationship among the different parts of the healthcare systems.

However, the hospital continues to have a symbolic role in the eyes of the community of reference: it is both the possible answer to health needs and the tangible sign of all the welfare systems and the progresses reached by the community (McKee e Healy, 2002). From here we have the difficulties accompanying all the deliberate actions on physical and functional arrangements of hospitals, also in the cases representing a clear improvement in terms of efficiency of the services offered.

In the recent past, the healthcare companies have hardly introduced systems to control the management mainly 
for three reasons:

1. the lack of significant economic, competitive and normative pressures;

2. the reluctance of professionals;

3. the weakness of programming and control functions.

Due to regionalisation and managementisation, as well as to a systemic crisis, the loss of the first condition has determined the need to introduce systems of strategic management of Italian Public Health Companies performance, going beyond the reluctance of professionals.

As a paradox for its symbolic value, the concept of hospital (in some regions and areas) is undergoing changes in its definite character. If the building is the symbol to safeguard, all the internal aspects may change significantly starting from the importance of the activities that are not related to hospitalisation. And its pertinence to the needs increasingly depends on the network of services in which the building and the services offered are included.

The reforms of managementisation of the National Health system, along with the latest expenditure restraint policies have increased the level of competitiveness of the companies providing the Italian health system.

Many hospitals are changing their main asset in terms of specialisations offered, level of health care and treatment provided, services offered and divisions. These changes are necessary to meet the different pressures that affect the medical sector, both in terms of demand (epidemiologic and demographic changes, higher expectations of patients, etc.) and supply (economic and financial trends move towards rationalisation, higher awareness of risks and disadvantages deriving from the lack of concentration of medium-high complexity and state-of-the-art technologies, etc.).

The answer to this phenomenon is the position that the public and private healthcare companies take with respect to their 'strategic role', that is a discretion and action sphere required by the management to take long-term choices.

In this context, it is interesting to analyse how the healthcare companies change their governance models according to the new challenges.

The first model used in the management of services is represented by the public and private mixed-economy enterprise, which may be used after some economic and juridical evaluations. On one hand, the mixed enterprise allows the healthcare company to arrange a business organisation with a high management flexibility; on the other hand, the asset autonomy, which is typical of the mixed enterprise, allows to realise a clear separation of the activity both at a juridical level and, in particular, at an economic and financial one. The main interest of the healthcare company is the possibility to manage a service with a business logic in order to act with a greater flexibility and cost-effectiveness - a solution that is not always possible with other forms provided for by the rules.

In particular:

a) as they act in an accreditation scheme, they are affected by the dynamics of the public environment: for instance, the lack of price when the patients receive health services provided by the Regional Health System; or the dependence concerning the planning and programming of cash flow on regional contingency of expenditure restraint;

b) as they have a private law legal personality, they are interested by logic and rules of enterprise, i.e. the presence of actual market mechanisms and, as a consequence, of an economic assessment that expresses its cost-effectiveness level. Though there is a level of interdependence with the NHS rules, the private accredited healthcare companies have a great space and a strategic autonomy that they express through the business solution (Coda, 1988).

One of the main actions carried out at an international level to innovate the public sector as a business is the introduction of forms of market to provide public services by means of the accreditation of private law legal personalities.

Instead, as for public businesses, the governance model has been focusing on the strategic vision of the clinic with respect to the requests of the ambit of reference: on one hand, efficiency requirements in the use of resources requiring a relocation of specialist and therapeutic activity from a traditional hospitalisation to a new one that uses less resources in ambulatory care - given the technical and technological possibilities of this shift. On the other hand, imaging and laboratory medicine offer other scanning solutions enriching the diversification 
of services.

Moreover, the ambulatory care theme is increasingly important in regional health policies. For instance, one of the objectives of the Director-Generals of Emilia Romagna is the implementation of accurate clinical and organisational solutions for ambulatory cares 'aimed at improving waiting times of the services offered; the development of the ambulatory "day service"; the improvement of prescription and providing accuracy for specialisation; the improvement of the prescription and check-up reservation cycle to facilitate citizens; the proper management of the reservation lists'.

These considerations are broadly applied for outpatient health services (i.e. ambulatory care) on which the system is aiming to look for forms of supply that are more appropriate and efficient from an organisational point of view, with respect to the change of the epidemiologic, technologic as well as economic and political framework (Health pact 2014-2016).

Outpatients are users of healthcare services whose medical conditions and diagnostic and thera-peutic treatments do not require a hospitalisation of more than one day. The services for the most common and traditional outpatients are ambulatory medical examinations, laboratory ser-vices and imaging.

However, at the present day companies have the possibility to implement many outpatient treatment options. The ambitious and complex challenge for companies is to reformulate the management models towards a progressive development of new processes both inside the hospi-tals and non-hospital infrastructure, in addition to 'one-shot' services (Carbone et al. 2014).

In the last years, according to the decrease in the number of hospitals, both in the public and ac-credited private sectors there is a prevalence of non-hospital local infrastructure (in 2012, about $70 \%$ for public structures, $93 \%$ for accredited private structure, compare with Table 10.1). The scene becomes different if considering the number of infrastructures in relation to the resident population and the impact of the accredited private in each region.

Thus, the crucial role of the ambulatory care in the future of health services must be understood. As it happened in the past with production business asset (ambulation, operating room, emergency room, etc.) the comparison of the business experience on ambulatory management processes may be so useful to identify best practices.

As for accessibility, usability and cost-effectiveness of health services rising strategies, the inter-national debate deals with new methods of healthcare supply included in the retailment in the health sector.

The 'retailisation' of Health for healthcare companies, that is the use of tools of retail manage-ment - such as flagship shops, fidelity cards and 'package deals' - is an increasingly important phenomenon in our country, fostered by the entrance of multinational corporations in Italy that are introducing this model from the US and Spain, countries where it started first (Alexander, 2008; Hunter et al., 2009; Keckley et al., 2008; Mehrotra et al., 2008; Mullin, 2009; Rozga, 2009; Rudavsky, 2009; Williams et al.). Thus, more frequently the city streets are full of healthcare centres that seem simple shops as for design and marketing. Sometimes, these centres give the patients fidelity cards, or pharmacies sell generic medicines along with original medi-cines. Healthcare services are increasingly related to product sale, traditional communication is tied to merchandising, doctor's offices in residential buildings are replaced by healthcare centres on the streets. After conquering branded industries, and then financial services providers and banks, the retailisation is increasingly spreading - even with some particularity of the sector, in Italy too.

Also, according to a recent study carried out by the Department of Internal Medicine in Barcelo-na, these are the alternative to the traditional hospitalisation: day centres (DC), quick diagnostic units (QDU), hospitals-at-home (HAH) and, in some circumstances, telemonitoring. These meth-ods are to be tested in terms of efficiency, although, some studies confirm that HAH may facili-tate hospital discharge for patients affected by chronic diseases, improving results and reducing costs.

The companies providing health care services are increasingly characterised for their different organisational identity in designing the supply of services (Schein, 2006). Organisations oriented to medical services are ruled by a technical and specialist culture (user-oriented), organisations focused on the values that they are able to create are ruled by a culture oriented to service de-sign, with a particular focus on the users to choose and to address to (Fosti and Longo, 2013).

As for governance asset development oriented to an efficient economic and financial sustaina-bility, a crucial role is played by the research of methods and tools to support strategic decisions that are able to give an overview on the relevant scope of assessment, as well as promoting a medium-term orientation of corporate governance choices. Economy and business experts should foster the transmission of the relevant information 
and indicators, overtaking the risk of over-accumulation of data typical of systems oriented to operation management in order to fo-cus them on the aspects determining long-term results, quality growth and business strength.

\section{Micro-Organisational Redesign Tools for the Economic Sustainability}

Traditionally, the management and cost control systems were interpreted as one of the main means of managementisation in the healthcare sector (Casati, 2000; Anessi Pessina \& Pinelli, 2003; Lecci \& Longo, 2004). Twenty years after the formal start of the managementisation process of the National Health Service companies, design and control systems in healthcare companies are mainly examined for their general features, the most used tools and their capability to foster a cultural change in the healthcare companies (Lecci and Vendramini, 2011).

However, the contributions analysing how the design and control systems change in contexts characterised by dynamism, interconnection and economic stress haven't find a great place.

The need to examine in depth this link is critical if we consider that the use of state-of-the-art control systems that are able to meet the issues of financial and economic constraints is a mandatory step in the healthcare sector. And this to go beyond some of the typical weaknesses of the traditional systems, in particular:

a vertical interpretation and an analysis of organisational costs (cost centre or responsibility centre);

a focus inside the organisation;

a quite limited diagnostic potential;

an orientation to the present management, with clear reluctances to new logics.

Thus, one of the first needs in terms of control is to understand the business result logic. Although, the summary reports of the management control must relate to the information requirement connected to the decisional and management processes of the healthcare governance stakeholders.

In this regard, since its origins, the senior management posts in the health sector have been characterised by the presence of a high specialisation with respect to the rules included in the art. 19 of the legislative decree $165 / 2001$.

On the top of the company there is the so-called business top management which includes the Director-General, chosen by the regional government on the basis of the approved health programmes, the hospital administrator and the medical director, chosen by the Director-General.

At a lower level, there is the operational management, divided into medical and healthcare role - ruled by the legislative decree 502/1992 and legislative decree 165/2001 for the profiles not expressively governed - and professional, technical and administrative management role mainly ruled by the legislative decree 165/2001, except for specialties included in the legislative decree 502/19925.

According to the law, the management fulfils the role of strategic guidance, design and business resources coordination.

Therefore, the governance structure introduced in the National Health System with the managementisation process highlights the strategic role of the Director-General .

Thus, the present paper takes into consideration the Director-General as the address body of the healthcare companies governance and, as a consequence, is the main focus.

With regard to this, the general directors taken into consideration in the study by Buccoliero, Marislio and Mattavelli concerning the need of the top management in terms of guidance system expressed a major information requirement for corporate governance activities ( 56 per cent), 44 per cent for the management of relationship with third party actors (such as Region, Ministry, conference of mayors of the municipalities included in the business area, trade union organisations, associations, etc.).

With respect to the level of structuring of data/information, the interviewees declared they mainly need highly structured reports (74 per cent) whose purpose is to support management, programming and business control activities. It is a group of periodical documents structures to allow:

- $\quad$ The monitoring of the activities provided and their resource consumption;

- The monitoring of revenues and business costs;

- The control of the quality of services (analysis of healthcare mobility, of the level of freelance activities, of waiting times); 
- The definition of the budgets for each organisational unit as well as the structure of the performance indicators highlighting the positive and negative difference with the objectives set;

- The possibility to adopt alternative strategies to modify critical situations and define new policies of guidance.

From a practical side, at present it is clear that healthcare companies must compare them to an increasingly variable environment and ever-more demanding stakeholders - this is why a strategic approach is necessary to face the issue.

Indeed, the business systems are able to give good-quality data, though the information is the real issue as it is too detailed and not able to convey the real message. In fact, the information is the subjective element, i.e. what the reader 'understands' and perceives.

An efficient control system of (in)efficiencies entails a proper overturning system of shared costs and an interrelated transfer pricing system, as well as being able to convey the right message among the different elements of the company.

Thus, it is necessary to start a consideration on the information capability of the reports carried out in the field of guidance control, which with the development of the abovementioned governance models will have to add data and information for the most observant and demanding users as well as the most varied stakeholders with respect to the previous addressee of the reports of the healthcare public bodies.

A cost-effective management of a company implies the capability to control which objectives set have been actually achieved through the examination of the obtained results. Thus, it is necessary a variety of operational tools to measure, analyse and interpret the activities carried out (Ferretti e Zangrandi, 2009).

Starting from the critical aspects arising from the analysis, the guidance system should allow the comprehension of the causes that brought to reach a goal (Doyle, 2002), since only the acknowledgement of the causes determines the capability to guide and manage the final result.

A summary and limited measure of cost centres (partial view) deal with the economic analysis needs of the production holdings, in which, through a unique production process that gives life to simple products, uniform needs for a well-defined class of users are satisfied.

As the technologies used, the services provided, the increase of the users helped, a measurement that is not coherent with the top management information requirement do not allow managing the different partial economic combinations. Concentrating on the single partial economic combination, the traditional systemic and analytic measurement allows measuring the contribution offered to the economic result, brings out the critical aspects and facilitates the management of the efficacy and efficiency levels of each combination.

To analyse in terms of structure means to choose the way to reorganise the costs classified by nature in the general accounting: in particular it is necessary to determine how these costs may be related to the size describing the business operating procedures (Banker and Johnston, 2007). The choice of subjects - with reference to which join the information of costs and activity - derives from the need to represent the methods for obtaining the business results in two ways: (i) competitiveness (type of service); (ii) organisation (cost centres). In other words, two actual facts are required to obtain factual, solid and indisputable evidences concerning the direction of governance showing the areas of inefficiency - that need operating rules - in order to solve the issue at its root, at the heart of the organisation.

Starting from Amaduzzi's theories and in view of the on-going perspectives in the health field, it is interesting to note that the analysis of the economic effects of business decisions and operations is carried out by means of the business economic audit system, which aims at observing how the acts relating to management change into economic value and, in their turn, into management acts for their capability to highlight the objectives reached by the business and institution.

The first wave of managementisation was mainly focused on the challenging business strategies and on the management control oriented to plan the mix, the volume of business and the relative resources. As a result of the stimulus from the business strategies and planning, the healthcare companies were expected to be able to modify spontaneously their processes improving the results as a consequence.

The internal life of the operational units was rarely studied and poorly understood. The people in charge of the operational units were expected to produce improvements without analysis on micro-organisational redesign tools.

Instead, the second phase of the managementisation process shows the need to examine in depth each operational 
unit, giving the managers the proper tools for the analysis and micro-organisational redesign in order to achieve a significant clinical improvement. In this sense, the debate concerning the management by process and the 'clinical management' may be an extremely positive indicator.

The interpretive force of the concept of 'process' and 'management by process' shows how the managementisation of the system is taking more space in the healthcare organisations, facing the analysis and redesign of their basic operating methods.

The concept of 'process' allows going back to the basic notion of 'anatomy' of the company and its organisation. This allows reading and interpreting healthcare companies from a new viewpoint. For its elementary nature, the concept of 'process' is a cornerstone that allows interpreting partial realities to lead back to a uniform framework with correlations and/or overlapping.

The elementary actions that are analysed through the interpretation of processes prove that the business incident cannot be divided into its technical-health dimension and organisational dimension, representing two sides of the same coin or two aspects of the same process. The process is studied in its clinical and organisational dimension at the same time.

Thus, the choice of the principles used to apply and select the weakest processes to reorganise corresponds to rational logics - even if they are not always explicit and aware of the actual strategic impact. Sometimes, the choice is lead by managers' pressures, other times by regional pressures, in some other cases by chance, which afterwards becomes malpractice (this does not necessarily correspond to the most poorly organised situations).

In our opinion, the most important issue is to spread, among medical professionals, the awareness that the acknowledgment of tools like the management by process, through the analysis of the proper reports, should be an expertise of the actors of the strategic management willing to rely on scientific evidences in order to minimise the difference of treatments, the rationalisation of costs and the risks of sustainability for a long-lasting view .

The management by process should be distributed widely, engaging all the units and the top-ranking posts of the healthcare companies, but in particular it should be diffused among all the companies of the country. It implies a very promising approach that is able to produce important results for patients, great satisfactions for promoters and be extremely useful for professionals.

This 'multidimensional' view of governance management and control is a cornerstone for businesses. It is able to do an uninterrupted steering of managers to lead to the adoption of new rules of behaviour that become the cultural heritage of the organisation to guide, project by project, the improvement of hospitals - more necessary than ever with the present challenges. A continual improvement that should be able to go beyond the present paradox of companies: if the increase of productivity fostered by a better operational management is not a synonym of cost-effectiveness, why should we invest in this direction if the company risks an increase of variable costs, against the funding limits set? This is a way of thinking spread in the public (and accredited private) healthcare system for a period of time. The new emerging infrastructure must demonstrate that the challenge of sustainability in the healthcare companies is feasible and urgent.

The challenge is to transform an underlying need into demand and meet it with a solid and widespread supply of tools of professional development.

Indeed, the health sector needs to measure costs through the analysis of the organisation processes. This implies addressing the governance systems towards a greater attention. The development of the rising governance models is oriented to the multidimensional systems, designed to monitor the different areas of management (economic and financial, expertise and professional developments, operational efficiency, customer and institution relationships, etc.).

Thus, it is necessary a model aiming at contrasting the "operational arrest" situations - typical of the phases in which a strong pressure of demand must confront to a growing scarcity of available resources - favouring an overview of the convenience and potential impact of strategic choices to take; at improving the quality of the information available to the governance bodies through an evidence-based approach; and finally at assuring a more qualified outcome and an economic and financial strengthening of businesses.

\section{Micro-organisational Redesign Tools for the Economic Sustainability}

A hundred years of studies of business economics and organisational science outline how the individuals and groups physiologically develop a series of behavioural dynamics of 'defence' with respect to business expectations of performance improvement.

In particular, organisations are satisficing, in the sense that they 'settle' to work following ac-ceptable 
performance levels, do not search for an improvement even if in the majority of cases they have a 'comfort bunker' made of practice, customs, organisational ceremonies ('we have always done this...') to protect themselves. This leads to 'closed and self-referential systems', also with internal subjects like the organisational units - the other elements of the same company.

Instead the correlation between performance audit and organisational management helps organi-sations and people to have a clear comprehension of the performance issues, gives life to change, reduces the satisficing trends and cancel 'short-sights' that may negatively affect the business management. In short, a multidimensional detection of the business elements may al-low the (healthcare) companies to leap from mediocrity to excellence and continuous improve-ment.

From this viewpoint, it is clear that the economic performance tools are a crucial element, though not mandatory, to set accurate objectives and help managers in the efficient guidance of business governance.

In fact, quantitative information is not able per se to satisfy the expectations of the different business bodies. And this is why they reflect only some aspects of the activities, of the difficul-ties of comprehension of representative models and its interpretation of results, of the features of receivers and their information requirement.

From this, we understand how the traditional information sub-system is able to reach the objectives set only partially.

If on one side, detection and performance audit systems of governance are related to the no-tion of quantitative detection models (accounting and extra-accounting) - though they use cut-ting-edge technologies - on the other, Business Economics has a role in the governance in completing the content of the business information sub-system, defining methods and tools to describe the quality that more and more characterises the life and development of businesses.

In conclusion of this paper, the pertinence and modernity of thoughts concerning the relation-ship between business detection data systems and governance tools are to be confirmed.

In this framework, the objective of future studies is to objectify through a market survey the in-formation gaps detected by the top-level management for the micro-organisational redesign of a governance system based on scientific evidences, in order to minimise the difference of treat-ments, to rationalise the costs and the risks of sustainability on a long-lasting view.

The empirical analyses will be focused on the investigation of the features of the governance control system adopted by a sample of Italian healthcare companies undergoing a reorganisation of processes to verify the correlation level between the detection of inefficiencies, the response capacity of the Director-Generals and the redesign of the critical process.

The evidence-based methodological approach will show that the effectiveness of the system of (in)efficiencies control implies a suitable summary data-processing system, as well as being able to convey the right message throughout the business.

In other words, objective evidences are necessary to take the way of thinking toward solid fac-tual evidences showing the areas of inefficiency, the areas that require operational rules in order to solve the problem at its root, at the heart of the organisation.

\section{References}

Aconis, A., Lincoln, K., \& Thomassen L. (2009). Retailization: Brand Survival in the Age of Retailer Power. Kogan Page.

Alexander, K. J. (2008). Health plans embrace retail clinics. Managed Care, 17(3), 32-34, 43. http://www.tandfonline.com/doi/abs/10.1080/07359683.2011.595648

Bergamaschi, E. C. (2000). Sviluppo del modello organizativo dipartimentale nelle strutture ospedaliere. In E. Anessi Pessina, E. Cantù (Eds.), Rapporto Oasi 2000. L'aziendalizzazione della sanità in Italia (pp. 247-277.). Egea, Milano.

Bertoli, G., \& Busacca, B. (2009). Customer Value. Soddisfazione, fedeltà, valore, Milano, Egea.

Borgonovi, E., \& Tarricone, R. (2012). "Pre-face”, in E. Cantu' (by), Rapporto Oasi 2012. L'aziendalizzazione della sanità in Italia, Egea, Milano.

Brower, A. (2006). Retail medical clinics draw patients and payers. Managed Care, 15(6), 33-36.

Carmignano, G. (1993). La marca commerciale. Il ruolo della «Private label» nella distribuzione moderna, 
Milano, EtasLibri.

Castaldo, S. (2007). Trust in Marketing Relationships. Edward Elgar, Cheltenham, UK.

Castaldo, S. (2008). Channel \& Retail Management. Milano, Egea.

Castaldo, S. (2010). Go to market, Il Mulino.

Castaldo, S., \& Mauri, C. (2005). Store Management. La gestione delle piattaforme relazionali, Franco Angeli.

D’Aveni, R. (1994). Hypercompetition. Managing the Dynamics of Strategic Manoeuvring. New York, Free Press.

Fosti, G., Larenza, O., Longo, F., Rotolo, A (2013). Governare la domanda di servizi socio-sanitari: Evidenze dalla Regione Emilia - Romagna, Mecosan, n. 88/2013.

Grönroos, C. (2007). Management \& marketing dei servizi, ISEDI.

Guenzi, P. (2002). La vendita relazionale, Milano, Etas.

Hansen-Turton, T., Ryan, S., Miller, K., Counts, M., \& Nash, D. B. (2007). Convenientcare clinics: The future of accessible health care. Disease Management, 10(2), 61-73. http://dx.doi.org/10.1089/dis.2006.636

Hunter, L. P., Weber, C. E., Morreale, A. P., \& Wall, J. H. (2009). Patient satisfaction with retail health clinic care. Journal of American Academy of Nurse Practitioner, 21, 565-570.

Keckley, P. H., Underwood, H. R., \& Gandhi, M. (2008). Retail clinics: Update and implications.

Mallarini, E. (2004). La fiducia in sanità. Non solo Marketing, Milano, EGEA.

Mallarini, E. (2012). Brand name vs generic drugs: e se a vincere fossero le private label? Mecosan, 80.

McCarthy, E. J. (1960). Basic marketing: A Managerial approach. Homewood, IL, Irwin.

Mehrotra, A., Wang, M., Lave, J. R., Adams, J. L., \& McGlynn, E. A. (2008). Retail clinics, primary care physicians, and emergency departments: A comparison of patients' visits. Health Affairs, 27, 1272-1282. http://dx.doi.org/10.1377/hlthaff.27.5.1272

Mullin, K. (2009). Considering retail health clinics. The Journal of Nursing Administration, 39, 531-536. http://dx.doi.org/10.1097/NNA.0b013e3181c1809b

Rozga, K. (2009). Retail health clinics: How the next innovation in market driven health care is testing state and federal law. American Journal of Law and Medicine, 35, 205-231.

Rudavsky, R., Pollack, C., \& Mehrotra, A. (2009). The geographic distribution, ownership, prices, and scope of practice at retail clinics. Annals of Internal-Medicine, 151, 315-320. http://dx.doi.org/10.7326/0003-4819-151-5-200909010-00005

Sabbadin, E., \& Negri, F. (2009). Flagship store e temporary store: la brand retailization, Atti de 8th International Marketing Trends Congress, 16-17 gennaio 2009, Paris (France).

Weitz, B., \& Bradford, K. (1999). Personal selling and sales management: a relationship marketing perspective. Journal of the Academy of Marketing Science, 27(2), 241-254. http://dx.doi.org/10.1177/0092070399272008

Williams, C. A., Khanfar, N. M., Harrington, C., \& Loudon, D. (2011). Marketing Retail Health Clinics: Challenges and Controversies Arising From a Health Care Innovation. Health Marketing Quarterly, 28, 270-285. http://dx.doi.org/10.1080/07359683.2011.595648

Yin, R. K. (1994). Case Study Research: Design and Methods (2nd ed.). Newbury Park, CA: Sage Publications. http://dx.doi.org/10.1111/j.1540-4781.2011.01212_17.x

Zaghi, K. (2008). Atmosfera e visual merchandising: ambienti, relazioni ed esperienze, Franco Angeli.

\section{Copyrights}

Copyright for this article is retained by the author(s), with first publication rights granted to the journal.

This is an open-access article distributed under the terms and conditions of the Creative Commons Attribution license (http://creativecommons.org/licenses/by/4.0/). 